\title{
Efficacy of humanized single large doses of caspofungin on the lethality and fungal tissue burden in a deeply neutropenic murine model against Candida albicans and Candida dubliniensis
}

This article was published in the following Dove Press journal:

Infection and Drug Resistance

\section{Eszter Prépost ${ }^{1}$ \\ Zoltán Tóth' \\ David S Perlin ${ }^{2}$ \\ Rudolf Gesztelyi ${ }^{3}$ \\ Gábor Kardos' \\ Renátó Kovács ${ }^{1,4}$ \\ Fruzsina Nagy' \\ Lajos Forgács' \\ László Majoros'}

'Department of Medical Microbiology, Faculty of Medicine, University of Debrecen, Debrecen, Hungary; ${ }^{2}$ Public Health Research Institute, New Jersey Medical School-Rutgers, Newark, NJ, USA; ${ }^{3}$ Department of Pharmacology and Pharmacotherapy, Faculty of Medicine, University of Debrecen, Debrecen, Hungary; ${ }^{4}$ Faculty of Pharmacy, University of Debrecen, Debrecen, Hungary
Correspondence: László Majoros Department of Medical Microbiology, University of Debrecen, Nagyerdei krt. 98, Debrecen 4032, Hungary

Tel +36 52255425

Fax +365225 5424

Email major@med.unideb.hu
Background: Echinocandins are the first-line therapy for treatment of invasive Candida infections, but the mortality rate remains high, calling for novel strategies. Giving single larger echinocandin doses infrequently is an alternative regimen. Our aim was to test this novel approach in a neutropenic murine model.

Materials and methods: We compared the in vivo efficacy of single 10 and $40 \mathrm{mg} / \mathrm{kg}$ of caspofungin $(2.5 \times$ and $10 \times$ the normal humanized dose $)$ to that of the same cumulative doses of daily 2 and $8 \mathrm{mg} / \mathrm{kg}$ doses for 5 days against 2 each of wild-type $C$. albicans and C. dubliniensis as well as echinocandin resistant $C$. albicans. As a comparator, we tested daily $1 \mathrm{mg} / \mathrm{kg}$ amphotericin B.

Results: In lethality experiments, all caspofungin and amphotericin B regimens improved survival against wild-type $C$. albicans and $C$. dubliniensis clinical isolates $(P<0.0001)$ and decreased the mean fungal kidney burdens of both species compared to controls. However, fungal kidney burden decreases were not always statistically significant, especially with single 10 or $40 \mathrm{mg} / \mathrm{kg}$ caspofungin doses. Amphotericin B was the least active drug against wild-type C. albicans. Against echinocandin-resistant strains, monodose $40 \mathrm{mg} / \mathrm{kg}$ caspofungin and $1 \mathrm{mg} / \mathrm{kg}$ of daily amphotericin B were effective in lethality experiments. Although, significant kidney CFU decreases were never found, except for amphotericin B against one of the isolates ( $p<0.05$ at day 3 and $p<0.001$ at day 6 ).

Conclusion: Single $40 \mathrm{mg} / \mathrm{kg}$ caspofungin and $1 \mathrm{mg} / \mathrm{kg}$ amphotericin B proved to be effective in the lethality experiments against wild-type and echinocandin-resistant C. albicans and wild-type $C$. dubliniensis. This was not always shown regarding fungal tissue burdens. Single caspofungin doses used in mice in this study are attainable in humans as well, suggesting a potential place of this dosing strategy not only in prevention but also in curative treatment of evolved invasive Candida infections.

Keywords: humanized caspofungin doses, intermittent dosing regimen of echinocandins, Candida albicans complex, fungal tissue burden, echinocandin resistance

\section{Introduction}

The frequency of invasive Candida infections has increased worldwide in the last decades. Although the proportion of non-albicans Candida species increased significantly, $C$. albicans is still the most frequently isolated Candida species from normally sterile body sites. ${ }^{1-5}$ The mortality rate of invasive Candida infections is around $40 \%$, but in intensive care units, 50-75\% mortality rates were observed 
among critically ill patients even in case of $C$. albicans despite the introduction of echinocandins into the antifungal armamentarium..$^{2-4}$

Echinocandins (caspofungin, micafungin, and anidulafungin) inhibit the $\beta$-1,3-glucan-synthase in Candida species. ${ }^{6-8}$ This antifungal class shows excellent in vitro and in vivo activity against Candida species and has quickly become the first therapeutic choice for the treatment of candidemia and other forms of invasive Candida infections. ${ }^{9}$ Currently, echinocandins are administered as single daily intravenous doses with minimal side effects. ${ }^{8,9}$

The unacceptably high mortality rate caused by Candida infections has inspired physicians to give higher daily doses to severely ill patients as efficacy of echinocandins is correlated with $\mathrm{AUC} / \mathrm{MIC}$ or $\mathrm{C}_{\max } / \mathrm{MIC}$ parameters. ${ }^{6-8,10-14}$ However, dose escalation studies did not reveal any advantage in survival rate over the traditional lower, daily echinocandin doses. Another possible dosing strategy is using single, large echinocandin doses infrequently (eg, weekly) with the same cumulative dose as the daily divided doses. ${ }^{12,14}$ Such a dosing strategy was followed only for prophylaxis of esophageal candidiasis (300 mg micafungin given every other day versus daily $150 \mathrm{mg}),{ }^{12}$ but clinical data are still lacking as to how the mortality among patients with disseminated candidiasis is influenced by single larger echinocandin doses.

Therefore, the aim of our study was to determine the in vivo efficacy of single large caspofungin doses one day post-infection against four C. albicans (including two echinocandin resistant) and two C. dubliniensis isolates in a severely neutropenic murine model.

\section{Materials and methods}

\section{In vitro studies}

Two wild-type $C$. albicans isolates were derived from blood samples. Strain 3666 was isolated in 2004 from a 51-yearold male patient with $C$. albicans mediastinitis, while strain 2606 was isolated in 2014 from a 1-year-old girl with acute lymphoid leukemia. Two echinocandin-resistant $C$. albicans strains, DPL18 (F641S) and DPL20 (F645P), were isolated from normally sterile body sites during echinocandins treatment. C. dubliniensis isolates originated from our previous studies. ${ }^{15}$ MICs of caspofungin and amphotericin-B (both from Sigma, Budapest, Hungary) were determined using the standard CLSI method (M27-A3) in RPMI-1640. ${ }^{16}$ MIC values for caspofungin and amphotericin $\mathrm{B}$ were read visually after $24 \mathrm{hrs}$ using the partial and total inhibition criteria, respectively. C. africana, the third member of the C. albicans complex was not tested because of its poor replication ability in vivo, even in a neutropenic murine model. ${ }^{17}$ C. parapsilosis ATCC 22019 and C. krusei ATCC 6258 strains were used as quality control strains. ${ }^{16}$ All isolates were tested three times.

\section{In vivo studies}

\section{Mice and immunosuppression}

In the fungal tissue burden experiments BALB/c female mice (23-25 g) were given cyclophosphamide 4 days before infection $(150 \mathrm{mg} / \mathrm{kg}), 1$ day before infection $(100 \mathrm{mg} / \mathrm{kg}), 2$ and 5 days post-infection $(100 \mathrm{mg} / \mathrm{kg}) .^{13,18,19}$ In the lethality experiments, this immunosuppression was continued by administration of $100 \mathrm{mg} / \mathrm{kg}$ cyclophosphamide every third day until the end of the experiment at the 21st day. The Guidelines for the Care and Use of Laboratory Animals were strictly followed during maintenance of the animals; experiments were approved by the Animal Care Committee of the University of Debrecen (permission no. 12/2014).

\section{Lethality experiments}

Mice were assigned randomly to study groups (ten mice/ group) and were infected intravenously through the lateral tail vein (day 0 ). The infectious dose for $C$. albicans and C. dubliniensis was $2 \times 10^{4}$ and $2 \times 10^{5} \mathrm{CFU} /$ mouse, respectively, in volumes of $0.2 \mathrm{~mL}$. Inoculum densities were confirmed by plating serial dilutions on Sabouraud agar plates.

Treatment with Caspofungin (Cancidas ${ }^{\circledR}$, commercial preparation) and amphotericin B (Fungizone ${ }^{\circledR}$, commercial preparation) began $24 \mathrm{hrs}$ post-infection (day 1). Both drugs were purchased from our University Pharmacy and reconstituted according to the recommendation of the manufacturer. In case of wild-type C. albicans and C. dubliniensis isolates, six treatment groups were created (no treatment; $1 \mathrm{mg} / \mathrm{kg}$ amphotericin $\mathrm{B}$, or 2 or $8 \mathrm{mg} / \mathrm{kg}$ caspofungin daily for 5 days; and the corresponding single caspofungin doses of 10 and $40 \mathrm{mg} / \mathrm{kg}$ ). Higher single caspofungin doses (60 and $80 \mathrm{mg} / \mathrm{kg}$ ) led to cca. $80 \%$ mortality within 1 day suggesting toxicity of Cancidas ${ }^{\circledR}$. In case of the echinocandin-resistant $C$. albicans isolates, against which the daily $2 \mathrm{mg} / \mathrm{kg}$ for 5 days and its corresponding single $10 \mathrm{mg} / \mathrm{kg}$ doses were not effective $(100 \%$ mortality within 4 days in preliminary experiments), we used 4 treatment arms (no treatment, $1 \mathrm{mg} / \mathrm{kg}$ amphotericin B daily for 5 days, $8 \mathrm{mg} / \mathrm{kg}$ caspofungin daily for 
5 days and the corresponding single dose of $40 \mathrm{mg} / \mathrm{kg}$ ). All treatments were given intraperitoneally in a $0.5 \mathrm{~mL}$ volume.

All groups were monitored twice daily for lethality. ${ }^{18}$ After 21 days, survival rate was analyzed by KaplanMeier test; the effect of different caspofungin doses and amphotericin B was compared using the logrank test. ${ }^{17-19}$

\section{Fungal kidney tissue burden experiments}

At the beginning of the therapy, fungal kidney burden was determined after dissection of three untreated mice in case of each isolate (day 1 control burden). Treatment groups were assigned as in the lethality experiment, 1 treatment group included 14-15 mice. The infectious doses for C. albicans and C. dubliniensis were $10^{4}$ and $10^{5} \mathrm{CFU} /$ mouse, respectively.

On day 3 and 6, 7-8 mice were sacrificed; both kidneys from each animal were removed, weighed and homogenized aseptically in $1 \mathrm{~mL}$ of saline and serially diluted. Fungal tissue burden was determined by quantitative culturing. The lower limit of detection was 50 $\mathrm{CFU} / \mathrm{g}$ of tissue. Kidney burden on day 3 and 6 was analyzed using the Kruskal-Wallis test with Dunn's post-test. ${ }^{17-19}$

\section{Pharmacokinetics of single 10 and $40 \mathrm{mg} / \mathrm{kg}$ caspofungin in mice}

As the relationship of caspofungin doses (administered once) with $\mathrm{AUC}_{0-\infty}$ as well as peak plasma concentration $\left(\mathrm{C}_{\max }\right)$ values is linear in mice, ${ }^{13}$ published pharmacokinetic data on single 5,20 and $80 \mathrm{mg} / \mathrm{kg}$ caspofungin doses were used to calculate $\mathrm{AUC}_{0-\infty}$ and $\mathrm{C}_{\max }$ values for single 10 and $40 \mathrm{mg} / \mathrm{kg}$ caspofungin doses using GraphPad Prism 8.0.1 for Windows (GraphPad Software Inc., La Jolla, CA, USA) as follows:

(a) $y=6.324 x+170.7 ;\left(\mathrm{r}^{2}=0.97\right)$, where $y$ is $\mathrm{AUC}_{0-\infty}(\mathrm{mg} \cdot \mathrm{h} / \mathrm{L})$, and $x$ is the dose of caspofungin $(\mathrm{mg} / \mathrm{kg})$,

(b) $y=0.5333 x+15.33 ;\left(\mathrm{r}^{2}=1\right)$, where $y$ is $\mathrm{C}_{\max }(\mathrm{mg} / \mathrm{L})$, and $x$ is the caspofungin dose $(\mathrm{mg} / \mathrm{kg})$, with $\mathrm{r}^{2}=1$.

As human single caspofungin doses between 5 and $210 \mathrm{mg}$ also show similar pharmacokinetics, ${ }^{20,21}$ the single human doses corresponding to single mouse doses were determined using mouse $\mathrm{AUC}_{0-\infty}$ values and the following equation: (c) $y=1.809 x-9.614 ;\left(\mathrm{r}^{2}=0.9847\right)$, where $y$ is $\mathrm{AUC}_{0-\infty}$ $(\mathrm{mg} \cdot \mathrm{h} / \mathrm{L})$ and $x$ is the single caspofungin dose in human (mg).

\section{Results}

\section{MIC results}

MIC values for the quality control strains (C. krusei ATCC 6258 and C. parapsilosis 22019 ATCC strains) were within the published acceptable ranges. ${ }^{16}$ Caspofungin MICs for wild-type C. albicans clinical isolates were within the accepted clinical break-points (Table 1). ${ }^{16}$ DPL18 and DPL20 C. albicans isolates were resistant to caspofungin. ${ }^{16}$ Caspofungin MICs of $C$. dubliniensis isolates were never higher than the published epidemiological cut off value for $C$. dubliniensis $(0.125 \mathrm{mg} / \mathrm{L})$ (Table 1$){ }^{22}$ Amphotericin B MICs for the six isolates were within the published ECOFF values $(2 \mathrm{mg} / \mathrm{L})$ for the two species. ${ }^{23}$

\section{Pharmacokinetics of single 10 and $40 \mathrm{mg} /$ $\mathrm{kg}$ caspofungin in mice}

Single 10 and $40 \mathrm{mg} / \mathrm{kg}$ caspofungin produce 234 and $424 \mathrm{mg} \cdot \mathrm{h} / \mathrm{L} \mathrm{AUC}$, and 20.7 and $36.7 \mathrm{mg} / \mathrm{L} \mathrm{C}_{\max }$ values in mice, respectively. These AUC values in humans correspond to single $135 \mathrm{mg}$ and $241 \mathrm{mg}$ calculated caspofungin doses, respectively.

\section{Lethality}

All caspofungin and amphotericin B regimens improved the survival in case of the wild-type $C$. albicans and C. dubliniensis clinical isolates $(P<0.0001$, Figure 1$)$. At day 7 , the survival rates were $\geq 90 \%$ for all treatment arms. However, survival rates decreased to $10-30 \%$ and $20-30 \%$, respectively, by day 21 with daily $2 \mathrm{mg} / \mathrm{kg}$ and the corresponding single $10 \mathrm{mg} / \mathrm{kg}$ caspofungin doses in cases of $C$. albicans isolate 3666 and $C$. dubliniensis

Table I MIC values of caspofungin and amphotericin B against $C$. albicans and $C$. dubliniensis isolates

\begin{tabular}{|l|l|l|}
\hline \multirow{2}{*}{ Isolates } & \multicolumn{2}{|l|}{ MIC (mg/L) } \\
\cline { 2 - 3 } & Caspofungin & Amphotericin B \\
\hline C. albicans 3666 & 0.25 & $\mathrm{I}$ \\
C. albicans 2606 & 0.125 & $\mathrm{I}$ \\
C. albicans DPL18 (F64IS) & 2 & 0.5 \\
C. albicans DPL20 (F645P) & 8 & 0.5 \\
C. dubliniensis 108I & 0.125 & 0.25 \\
C. dubliniensis 2953 & 0.125 & 0.25 \\
\hline
\end{tabular}


3666

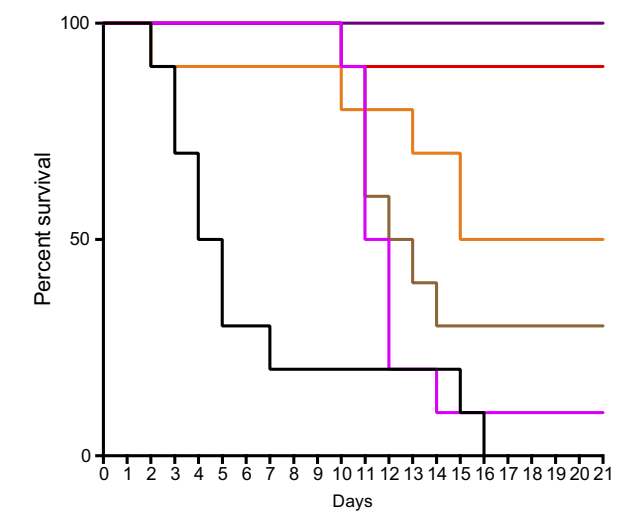

- Control $-2 \mathrm{mg} / \mathrm{kg} / \mathrm{day}$ CAS $-8 \mathrm{mg} / \mathrm{kg} / \mathrm{day}$ CAS $-10 \mathrm{mg} / \mathrm{kg} / \mathrm{once}$ CAS - $40 \mathrm{mg} / \mathrm{kg} / \mathrm{once}$ CAS $-1 \mathrm{mg} / \mathrm{kg} / \mathrm{day}$ AMB

1081

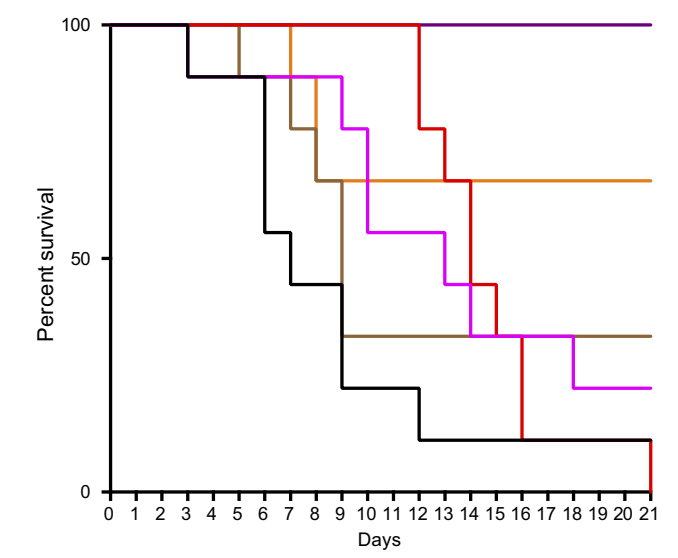

- Control $-2 \mathrm{mg} / \mathrm{kg} / \mathrm{day}$ CAS - $8 \mathrm{mg} / \mathrm{kg} / \mathrm{day}$ CAS $-10 \mathrm{mg} / \mathrm{kg} / \mathrm{once}$ CAS

- $40 \mathrm{mg} / \mathrm{kg} / \mathrm{once}$ CAS $-1 \mathrm{mg} / \mathrm{kg} / \mathrm{day}$ AMB

DPL18

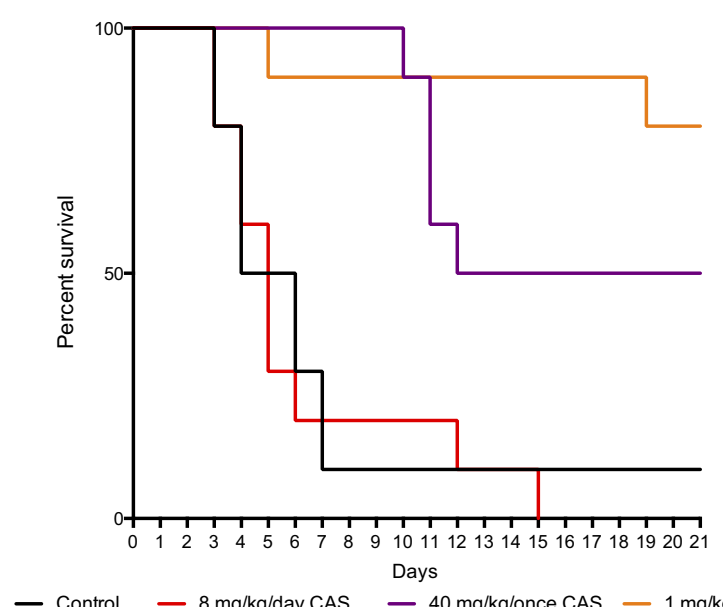

2606

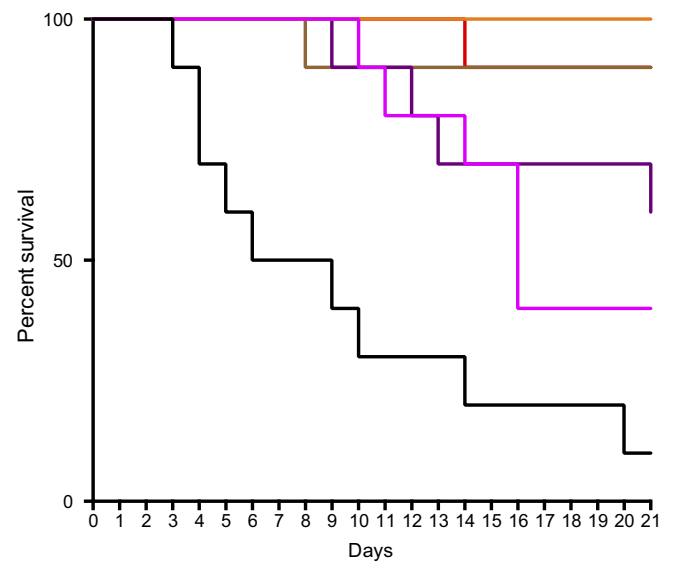

- Control $-2 \mathrm{mg} / \mathrm{kg} / \mathrm{day}$ CAS $-8 \mathrm{mg} / \mathrm{kg} / \mathrm{day}$ CAS $-10 \mathrm{mg} / \mathrm{kg} / \mathrm{once}$ CAS

- $40 \mathrm{mg} / \mathrm{kg} / \mathrm{once}$ CAS $-1 \mathrm{mg} / \mathrm{kg} / \mathrm{day}$ AMB

2953

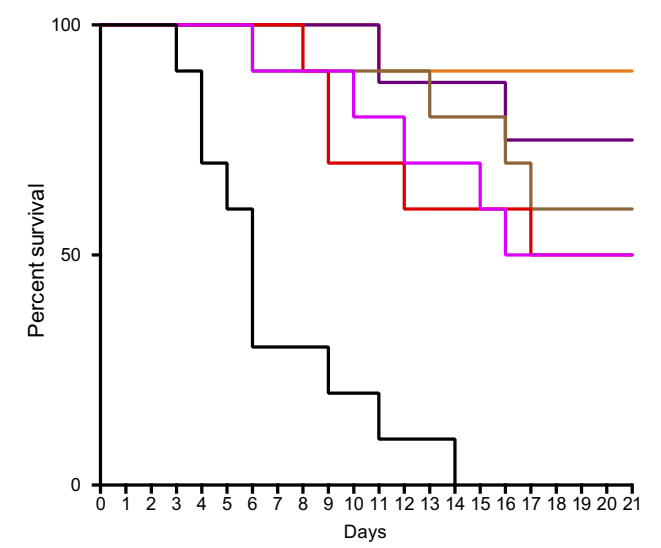

- Control $-2 \mathrm{mg} / \mathrm{kg} / \mathrm{day}$ CAS - $8 \mathrm{mg} / \mathrm{kg} / \mathrm{day}$ CAS $-10 \mathrm{mg} / \mathrm{kg} / \mathrm{once}$ CAS $-40 \mathrm{mg} / \mathrm{kg} / \mathrm{once}$ CAS $-1 \mathrm{mg} / \mathrm{kg} / \mathrm{day}$ AMB

DPL20

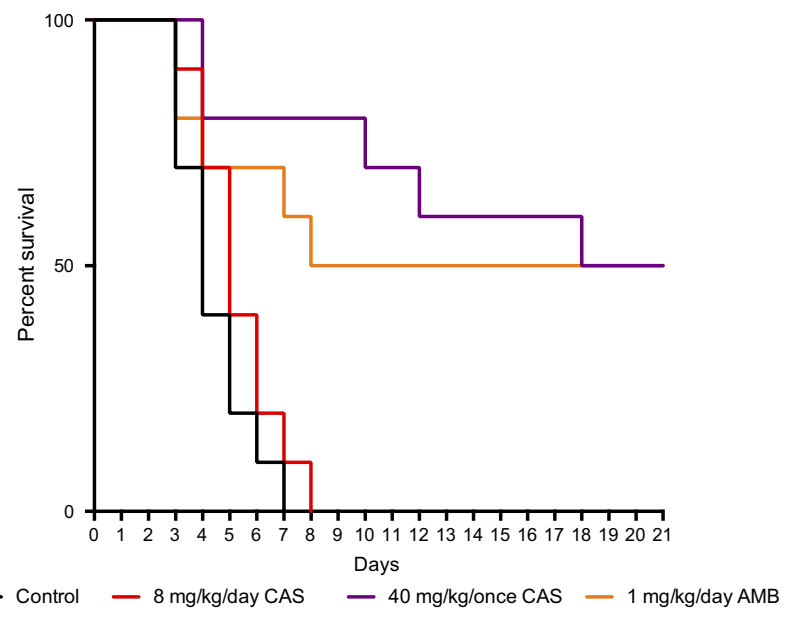

Figure I Survival of mice infected with echinocandin-susceptible C. albicans (3666 and 2606), C. dubliniensis (I08I and 2953) and echinocandin-resistant C. albicans (DPLI8 and DPL20). The infectious dose for echinocandin-susceptible and echinocandin-resistant C. albicans and echinocandin-susceptible C. dubliniensis were $2 \times 10^{4}, 2 \times 10^{4}$ and $2 \times 10^{5} \mathrm{CFU} /$ mouse, respectively. Intraperitoneal caspofungin and amphotericin B treatment were started $24 \mathrm{hrs}$ after postinfection. After $2 \mathrm{I}$ days, the survival rate was analyzed by Kaplan-Meier test. 
isolate 1081 . In contrast, daily $8 \mathrm{mg} / \mathrm{kg}$ led to no survival by day 21 , while the corresponding $40 \mathrm{mg} / \mathrm{kg}$ single dose resulted in $100 \%$ survival for these two isolates. Single dose $40 \mathrm{mg} / \mathrm{kg}$ was not inferior to the corresponding daily $8 \mathrm{mg} / \mathrm{kg}$ in case of the other two echinocandin susceptible isolates (2606 and 2953) either.

Survival rates of untreated controls at day 7 were lower in cases of echinocandin-resistant $C$. albicans isolates (0-10\%) compared to wild-type isolates $(20-50 \%)$. Daily $8 \mathrm{mg} / \mathrm{kg}$ of caspofungin did not improve the survival rates compared to untreated controls (10-20\% within 7 days). In, contrast single $40 \mathrm{mg} / \mathrm{kg}$ caspofungin and $1 \mathrm{mg} / \mathrm{kg}$ amphotericin B increased the survival rates significantly (to $80-100 \%$ and to $70-90 \%$ at day 7 , respectively; $P<0.0001$, Figure 1).

\section{Fungal kidney tissue burden}

At the beginning of therapy, the mean fungal tissue burden ranges were $2.6 \times 10^{5}-3.1 \times 10^{5}, 9.8 \times 10^{4}-1.1 \times 10^{5}$ and $4.8 \times 10^{4}$ $1.1 \times 10^{5}$ cells per mouse for wild-type $C$. albicans, echinocandin-resistant $C$. albicans and wild-type $C$. dubliniensis, respectively. Yeasts grew to $1.1-2.8,1.2-1.4$ and $2.8-3.3 \log$ units in cases of wild-type $C$. albicans, echinocandin-resistant C. albicans and wild-type $C$. dubliniensis, respectively, after 6 days in untreated control mice.

With wild-type $C$. albicans and C. dubliniensis, all caspofungin treatment arms decreased the mean fungal kidney burdens compared to controls on day 3 or 6 , but the fungal kidney burden decreases were not always statistically significant (Figure 2), especially for single 10 or $40 \mathrm{mg} / \mathrm{kg}$ doses. Fungicidal activity of daily 2 and $8 \mathrm{mg} / \mathrm{kg}$ of caspofungin ( $>3 \log$ decreases) was frequently observed for C. dubliniensis at day 6. In contrast, with $C$. dubliniensis isolate 1081 the fungal tissue burden was higher on days 3 and 6 compared to day 1 burden with single 10 and $40 \mathrm{mg} / \mathrm{kg}$ caspofungin. Amphotericin B treatment yielded higher fungal kidney burdens on day 6 (but not on day 3) in case of C. albicans than in the case of $C$. dubliniensis.

Against echinocandin-resistant C. albicans strain DPL18 (Fks-F641S), single $40 \mathrm{mg} / \mathrm{kg}$ caspofungin and $1 \mathrm{mg} / \mathrm{kg}$ amphotericin B led to 0.7 and 1.2 , and 0.8 and $2.0 \log$ CFU decrease comparing to day 3 and 6 controls, respectively (Figure 3), of which only amphotericin B produced significant decrease $(P<0.05$ and 0.001 on day 3 and 6, respectively). Against the DPL20 (FksF645P) isolate daily $8 \mathrm{mg} / \mathrm{kg}$ caspofungin, single $40 \mathrm{mg} /$ $\mathrm{kg}$ caspofungin and $1 \mathrm{mg} / \mathrm{kg}$ amphotericin B produced $0.08,0.25$ and $0.33 \log$ CFU decrease only on day 6 , respectively (on day 3 no CFU decrease was detected in any treatment arm), but these were not statistically significant ( $P>0.05$ for all doses).

\section{Discussion}

Increasing amounts of data suggest that the currently used standard echinocandin doses (caspofungin: $70 \mathrm{mg}$ loading dose, then $50 \mathrm{mg}$ daily; anidulafungin: 200-mg loading dose and then $100 \mathrm{mg}$ daily; or micafungin: $100 \mathrm{mg}$ daily) may be insufficient to cure invasive Candida infections among certain severely ill patients. ${ }^{10,11}$ The standard echinocandin dosing regimen may result in low echinocandin exposure in intensive care units, among patients with obesity, with severe burn injuries and patients with complicated intra-abdominal infections. ${ }^{24-28}$ In order to increase the probability of attaining therapeutic concentrations in infected body sites, several studies experimented with higher daily doses in treating invasive Candida infections. However, elevated daily doses of caspofungin and micafungin did not increase cure rates significantly. ${ }^{10,11}$ Our previous studies in a neutropenic murine model also confirmed that there were no significant differences in fungal tissue burden decreases between daily $3 \mathrm{mg} / \mathrm{kg}$, $5 \mathrm{mg} / \mathrm{kg}$ and 15 or $20 \mathrm{mg} / \mathrm{kg}$ caspofungin against echinocandin-susceptible C. albicans, C. glabrata and C. krusei, respectively. ${ }^{29-31}$ Against echinocandin-resistant C. albicans and C. glabrata even 16 or $20 \mathrm{mg} / \mathrm{kg}$ caspofungin were ineffective in reducing the fungal kidneys burden. ${ }^{19,29,30}$

Administering single larger echinocandin doses infrequently is another therapeutic option compared to divided smaller daily doses with the same cumulative doses. Fungal tissue burden experiments showed that single larger echinocandin doses were not inferior compared to daily treatment with the same cumulative dose for prophylaxis and treatment of invasive candidiases. ${ }^{19,32-35}$ Moreover, single larger aminocandin (an early echinocandin that stuck in phase I clinical trial) doses against C. albicans postinfection significantly increased the survival rates in a disseminated immunocompetent murine model. ${ }^{35}$ Infrequently given large doses are the recommended treatment regimen for a next-generation echinocandin agent, rezafungin (CD101); in phase 3 for treatment of candidaemia and invasive candidiasis. This dosing recommendation is based on findings that infrequent larger doses showed better fungal elimination (lethality data were not obtained) than daily doses against C. albicans. ${ }^{36}$ 


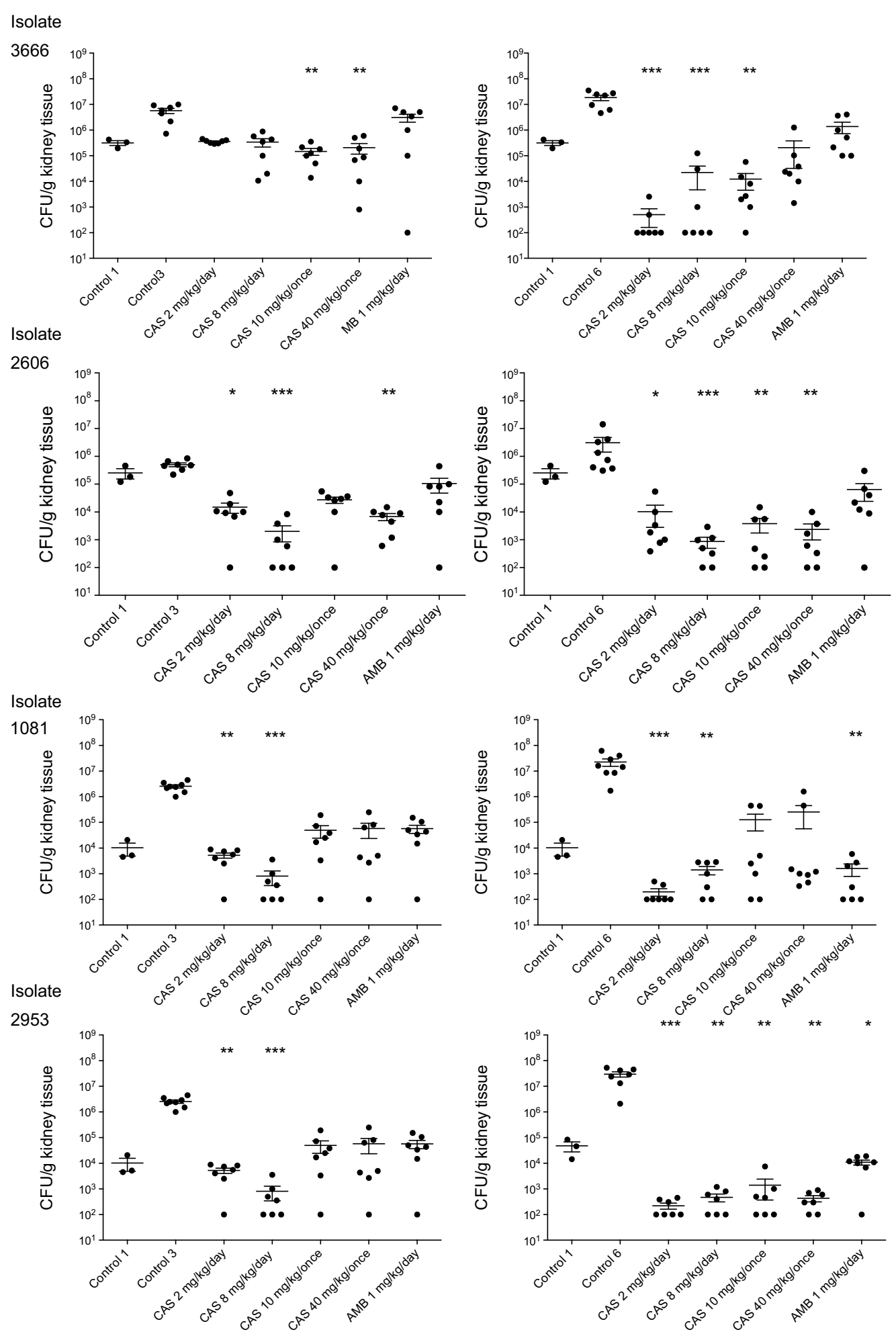

Figure 2 Kidney tissue burden of profoundly neutropenic BALB/c mice infected intravenously with C. albicans 3666, C. albicans $2606, C$. dubliniensis I08I and C. dubliniensis 2953. Fungal kidney tissue burden was determined at day 3 (left panel) and at the end of experiments on day 6 (right panel). Day I tissue burden is shown in all graphs for comparison (Control I). The bars represent the medians. Burdens of treated mice were compared to burdens of untreated controls measured on the same day of the experiment (Control 3 and Control 6 in the left and right panels, respectively). Level of statistical significance is indicated at $P<0.05(*), P<0.0$ I $(* *)$ and $P<0.00$ I (***). 

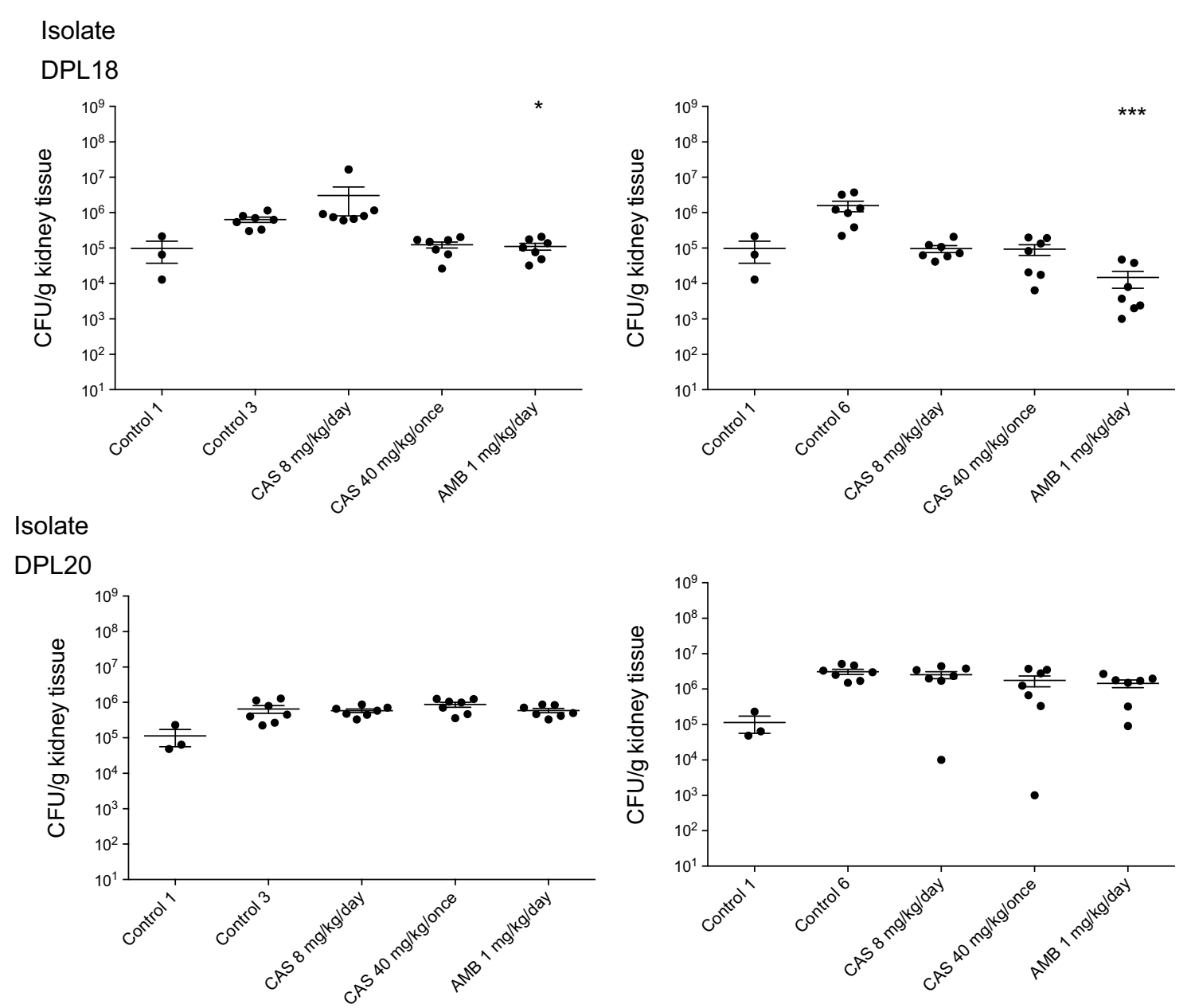

Figure 3 Kidney tissue burden of profoundly neutropenic BALB/c mice infected intravenously with DPLI8 and DPL20 echinocandin-resistant C. albicans isolates. Fungal kidney tissue burden was determined at day 3 (left panel) and at the end of experiments on day 6 (right panel). Day I tissue burden is shown in all graphs for comparison (Control I). The bars represent the medians. Burdens of treated mice were compared to burdens of untreated controls measured on the same day of the experiment (Control 3 and Control 6 in the left and right panels, respectively). Level of statistical significance is indicated at $P<0.05(*)$ and $P<0.001$ (***).

In this study in the first 7 days, single 10 and $40 \mathrm{mg} /$ $\mathrm{kg}$ caspofungin showed comparable efficacy on survival rates $(90-100 \%)$ as the daily, 2 and $8 \mathrm{mg} / \mathrm{kg}$ doses against wild-type $C$. albicans and $C$. dubliniensis strains in a persistently neutropenic murine model. Moreover, the effect of single $40 \mathrm{mg} / \mathrm{kg}$ but not $10 \mathrm{mg} / \mathrm{kg}$ caspofungin on survival rate persisted in the next 14 days as well, increasing the survival rates up to $60-100 \%$ for both species. This dose-dependent effect is not surprising, as single $40 \mathrm{mg} / \mathrm{kg}$ caspofungin produced significantly higher $\mathrm{AUC}$ and $\mathrm{C}_{\max }$ values than single $10 \mathrm{mg} / \mathrm{kg}$. Efficacy of echinocandins best correlates with a freedrug AUC/MIC (optimal ratio >10-20) or Cmax/MIC (optimal ratio $>1$ ) values. ${ }^{6-9,13,14,37}$ AUC/MIC value ranges produced by $10 \mathrm{mg} / \mathrm{kg}$ single doses were 32.8-65.5 for wild-type C. albicans and C. dubliniensis isolates calculating with $3.5 \%$ free-caspofungin, while $\mathrm{C}_{\max } / \mathrm{MIC}$ values were 2.9-5.8. In case of single $40 \mathrm{mg} / \mathrm{kg}$ caspofungin the free-drug AUC/MIC and $\mathrm{C}_{\max } / \mathrm{MIC}$ values were as high as 59.4-118.7 and 5.2-10.3, respectively. Fungal tissue burdens on day 3 and 6 were concordant with our lethality results at day 7; all regimens produced at least $1.95 \log$ decrease in day 6 tissue burden. However, in cases of echinocandinresistant C. albicans strains, the free-caspofungin $\mathrm{AUC} /$ MIC and $\mathrm{C}_{\max } / \mathrm{MIC}$ values even with the $40 \mathrm{mg} / \mathrm{kg}$ dose only were $1.9-7.4$ and $0.2-0.6$, respectively, predicting poor outcome in vivo. This was applicable to the fungal burden data, as the single large dose produced lower tissue burden decreases, but not for lethality data, where 7-day lethality was comparable, while 21-day lethality was more favorable in the $40 \mathrm{mg} / \mathrm{kg}$ caspofungin arm. 
This is in line with the widely accepted opinion that paradoxical growth may be confined to in vitro situations. $^{10,11,14,32}$

Similar difference between lethality and fungal burden results was reported by Najvar et al, ${ }^{35}$ comparing 5 and $30 \mathrm{mg} / \mathrm{kg}$ single-dose caspofungin in immunocompetent murine bloodstream infection model. Such short-term therapies as used in animal models of fungal infections are almost always reported deficient in sterilizing activity; indicating that for eradication a long-term therapy is crucial. $^{9,29-31}$ Interestingly, the calculated pharmacodynamic parameters predicted the weaker activity on the fungal burden well, while prognosticated poorly the clinical effect, ie, increased survival.

Similarity of the lethality rates of untreated controls suggests that there are no significant differences in virulence between wild-type and echinocandin-resistant isolates in bloodstream infection of neutropenic mice. Our finding is different from the results by Ben-Ami et al who found that fitness of the homozygous fks-1 mutant (S645F) strains is significantly lower than for wild-type strain. ${ }^{38}$ However, they used non-immunosuppressed BALB/c mice in their experiments. In accordance with the results of Wiederhold et al, ${ }^{39}$ daily $8 \mathrm{mg} / \mathrm{kg}$ of caspofungin at day 7 yielded only $20 \%$ survival rates both for DPL 18 and DPL 20 isolates indicating that elevated daily doses of caspofungin did not result in survival benefit compared to untreated controls. In this study, single $40 \mathrm{mg} / \mathrm{kg}$ caspofungin and daily $1 \mathrm{mg} / \mathrm{kg}$ of amphotericin B produced $80-100 \%$ and $70-90 \%$ survival against echinocandin-resistant isolates at day 7 , respectively. Moreover, single $40 \mathrm{mg} / \mathrm{kg}$ caspofungin prolonged the survival during the next 14 days as well, in spite of the low freecaspofungin AUC/MIC and $\mathrm{C}_{\max } / \mathrm{MIC}$ values.

The possible explanation for the efficacy of single $40 \mathrm{mg} / \mathrm{kg}$ of caspofungin against echinocandin-resistant isolates in the lethality experiments may be related to the protein-binding. Though in case of caspofungin the percent of the free fraction among healthy persons is $3.5 \%$ this value could be increased to $7.6 \%$ among persons with invasive Candida infections. ${ }^{37,40}$ Calculating with $7.6 \%$ free-caspofungin the $\mathrm{AUC} / \mathrm{MIC}$ and $\mathrm{C}_{\max } / \mathrm{MIC}$ values for isolate DPL18 $(\mathrm{MIC}=2 \mathrm{mg} / \mathrm{L})$ were 15.9 and 1.38 which are higher than the recommended 10 and 1 ratios, respectively. In case of isolate DPL 18, the fungal tissue burden experiments were in accordance with the lethality experiments (the CFU values were not increased compared to day 1 control; fungistatic effect). However, for isolate DPL20 $(\mathrm{MIC}=8 \mathrm{mg} / \mathrm{L}) \mathrm{AUC} / \mathrm{MIC}$ and $\mathrm{C}_{\max } / \mathrm{MIC}$ were 3.9 and
0.34, respectively, confirming that echinocandin efficacy is weak in decreasing the fungal tissue burden against isolates very high MICs (ie, $8 \mathrm{mg} / \mathrm{L}$ ) containing a prominent FKS1 hot-spot amino acid substitution (S645F). Another potential explanation is that a dose larger even than loading doses leads to more rapid increase in tissue drug concentration, ie, the peak concentration will be higher and reached faster. $^{14,34,36,37}$

Notably, survival rates in mice treated with single $40 \mathrm{mg} / \mathrm{kg}$ caspofungin were comparable in case of DPL20 isolate, in case of isolate DPL18 as well as in case of the echinocandin wild-type isolates.

Results obtained from our mice experiments can be translated to human as in earlier comparison outcomes in mice correlated well with treatment success in patients. ${ }^{13,14,41}$ The basis for this similarity is that the drug target is within the organism and is independent of the host; thus, free-drug AUC/ MIC or $\mathrm{C}_{\max } / \mathrm{MIC}$ needed for efficacy in a human must be the same as in a mouse. Single 10 and $40 \mathrm{mg} / \mathrm{kg}$ caspofungin produce 234 and $424 \mathrm{mg} \cdot \mathrm{h} / \mathrm{L}$ AUCs which correspond to single 135 and $241 \mathrm{mg}$ caspofungin in humanized doses. The largest single doses of caspofungin used in healthy volunteers were 150 and $210 \mathrm{mg}$ with minimal side effects suggesting that the maximum tolerated human dose still is not reached. $^{20,21}$ Inadvertent administration of up to $400 \mathrm{mg}$ of caspofungin in one day did not result in clinically important adverse reactions. ${ }^{40}$ Moreover, daily $200 \mathrm{mg}$ of caspofungin was well tolerated in phase II dose escalation study for the treatment of probable aspergillosis. ${ }^{42}$ Thus, elevated single dose of caspofungin (ie, 250 or $300 \mathrm{mg}$ ) probably can be used safely for the treatment of invasive Candida infections, though this assumption awaits confirmation.

In this study, we have found that humanized, single larger doses of caspofungin showed excellent in vivo efficacy both on the lethality as well as in fungal kidney burden experiments for the treatment of disseminated candidiasis caused by wild-type $C$. albicans and the closely related $C$. dubliniensis in a neutropenic murine model. It is noteworthy that not only $1 \mathrm{mg} / \mathrm{kg}$ of daily amphotericin B but single $40 \mathrm{mg} / \mathrm{kg}$ of caspofungin as well proved to be effective in survival studies with wild type and echinocandin-resistant $C$. albicans isolates with prominent mutations in the $f k s$ genes. However, this effect was not seen in the fungal tissue burden experiments. More importantly, single caspofungin doses for mice used in this study are attainable in humans as well, suggesting a potential place of this dosing strategy not only in prevention but also in treatment against evolved invasive Candida infections. 


\section{Acknowledgments}

The authors thank Katalin Orosz-Tóth for inoculation of mice. The study was supported by the EFOP3.6.3-VEKOP-16-2017-00009 program. Renátó Kovács was supported by the TÁMOP 4.2.4. A/2-11-1-20120001 National Excellence Program-Elaborating and operating an inland student and researcher personal support system. The project was subsidized by European Union and co-financed by the European Social Fund. Zoltán Tóth and Fruzsina Nagy were supported by the ÚNKP-18-3 New National Excellence Program of the Ministry of Human Capacities. László Majoros received conference travel grants from MSD, Astellas and Pfizer.

\section{Disclosure}

Mr Zoltán Tóth reports grants from the Ministry of Human Capacities, Government of Hungary, during the conduct of the study. Prof. Dr David Perlin reports a patent Pat \# 9657334 issued, a patent Publ \#20150125856 pending; and David Perlin serves on $\mathrm{SABs}$ and/or receives financial support from Merck, Astellas, Cidara, Scynexis, Amplyx, Martinas and N8. Dr Gábor Kardos reports grants from Hungarian Academy of Sciences, outside the submitted work. Ms Fruzsina Nagy reports grants from Ministry of Human Capacities, Government of Hungary, during the conduct of the study. Dr László Majoros reports grants from MSD, grants from Astellas, grants from Pfizer, outside the submitted work, and is currently part of an ongoing research project together with Cidara. The authors report no other conflicts of interest in this work.

\section{References}

1. Lausch KR, Søgaard M, Rosenvinge FS, et al. Treatment of candidemia in a nationwide setting: increased survival with primary echinocandin treatment. Infect Drug Resist. 2018;11(11):2449-2459. doi:10.2147/IDR

2. Lortholary O, Renaudat C, Sitbon K, et al. Worrisome trends in incidence and mortality of candidemia in intensive care units (Paris area, 2002-2010). Intensive Care Med. 2014;40:1303-1312. doi:10.1007/s00134-014-3408-3

3. Wang E, Farmakiotis D, Yang D, McCue DA, Kantarjian HM, Kontoyiannis DP. The ever-evolving landscape of candidaemia in patients with acute leukaemia: non-susceptibility to caspofungin and multidrug resistance are associated with increased mortality. $J$ Antimicrob Chemother. 2015;70:2362-2368. doi:10.1093/jac/dkv087

4. Colombo AL, Guimarães T, Sukienik T, et al. Prognostic factors and historical trends in the epidemiology of candidemia in critically ill patients: an analysis of five multicenter studies sequentially conducted over a 9-year period. Intensive Care Med. 2014;40:1489-1498. doi:10.1007/s00134-014-3400-y
5. Jung DS, Farmakiotis D, Jiang Y, Tarrand JJ, Kontoyiannis DP. Uncommon Candida species fungemia among cancer patients, Houston, Texas, USA. Emerg Infect Dis. 2015;21:1942-1950. doi:10.3201/eid2111.150404

6. Perlin DS, Shor E, Zhao Y. Update on antifungal drug resistance. Curr Clin Microbiol Rep. 2015;2:84-95. doi:10.1007/s40588-0150015-1

7. Perlin DS. Echinocandin resistance, susceptibility testing and prophylaxis: implications for patient management. Drugs. 2014;74:1573-1585. doi:10.1007/s40265-014-0286-5

8. Chen SC, Slavin MA, Sorrell TC. Echinocandin antifungal drugs in fungal infections: a comparison. Drugs. 2011;71(1):11-41. doi:10.2165/11585270-000000000-00000

9. Pappas PG, Kauffman CA, Andes DR, et al. Clinical practice guideline for the management of candidiasis: update by the Infectious Diseases Society of America. Clin Infect Dis. 2016;62:e1-e50. doi:10.1093/cid/civ933

10. Betts RF, Nucci M, Talwar D, et al. A multicenter, double-blind trial of a high-dose caspofungin treatment regimen versus a standard caspofungin treatment regimen for adult patients with invasive candidiasis. Clin Infect Dis. 2009;48:1676-1684. doi:10.1086/598933

11. Pappas PG, Rotstein CMF, Betts RF, et al. Micafungin versus caspofungin for treatment of candidemia and other forms of invasive candidiasis. Clin Infect Dis. 2007;45(7):883-893. doi:10.1086/ 520980

12. Andes D, Reynolds DK, Van Wart SA, et al. Clinical pharmacodynamic index identification for micafungin in esophageal candidiasis: dosing strategy optimization. Antimicrob Agents Chemother. 2013;57:5714-5716. doi:10.1128/AAC.01057-13

13. Andes D, Diekema DJ, Pfaller MA, Bohrmuller J, Marchillo K, Lepak A. In vivo comparison of the pharmacodynamic targets for echinocandin drugs against Candida species. Antimicrob Agents Chemother. 2010;54:2497-2506. doi:10.1128/AAC.01584-09

14. Gumbo T. Impact of pharmacodynamics and pharmacokinetics on echinocandin dosing strategies. Curr Opin Infect Dis. 2007;20:587-591. doi:10.1097/QCO.0b013e3282f1bea3

15. Szabo Z, Borbely A, Kardos G, et al. In vitro efficacy of amphotericin B, 5-fluorocytosine, fluconazole, voriconazole and posaconazole against Candida dubliniensis isolates using time-kill methodology. Mycoses. 2010;53(3):196-199. doi:10.1111/j.14390507.2009.01705.x

16. Clinical and Laboratory Standards Institute. Reference Method for Broth Dilution Antifungal Susceptibility Testing of Yeasts. Approved standard, 3rd ed. M27-A3. Wayne, PA: Clinical and Laboratory Standards Institute; 2008.

17. Kovács R, Saleh Q, Bozó A, et al. Killing activity of micafungin against Candida albicans, C. dubliniensis and Candida africana in the presence of human serum. Mycopathol. 2017;182(11-12):979-987. doi:10.1007/s11046-017-0178-9

18. Bayegan S, Szilágyi J, Kemény-Beke Á, et al. Efficacy of a single $6 \mathrm{mg} / \mathrm{kg}$ versus two $3 \mathrm{mg} / \mathrm{kg}$ caspofungin doses for treatment of disseminated candidiasis caused by Candida albicans in a neutropenic mouse model. J Chemother. 2011;23:107-109. doi:10.1179/joc.2011.23.2.107

19. Berényi R, Kovács R, Domán M, et al. Efficacy of single large doses of caspofungin in a neutropenic murine model against the "psilosis" group. New Microbiol. 2014;37(3):355-362.

20. Stone JA, Holland SD, Wickersham PJ, et al. Single- and multiple-dose pharmacokinetics of caspofungin in healthy men. Antimicrob Agents Chemother. 2002;46:739-745. doi:10.1128/ aac.46.3.739-745.2002

21. Migoya EM, Mistry GC, Stone JA, et al. Safety and pharmacokinetics of higher doses of caspofungin in healthy adult participants. J Clin Pharmacol. 2011;51:202-211. doi:10.1177/0091270010374853 
22. Pfaller MA, Castanheira M, Diekema DJ, Messer SA, Jones RN. Triazole and echinocandin MIC distributions with epidemiological cutoff values for differentiation of wild-type strains from non-wildtype strains of six uncommon species of Candida. J Clin Microbiol. 2011;49(11):3800-3804. doi:10.1128/JCM.05047-11

23. Pfaller MA, Espinel-Ingroff A, Canton E, et al. Wild-type MIC distributions and epidemiological cutoff values for amphotericin B, flucytosine, and itraconazole and Candida spp. as determined by CLSI broth microdilution. J Clin Microbiol. 2012;50(6):2040-2046. doi:10.1128/JCM.00248-12

24. Grau S, Luque S, Campillo N, et al. Plasma and peritoneal fluid population pharmacokinetics of micafungin in post-surgical patients with severe peritonitis. J Antimicrob Chemother. 2015;70:2854-2861. doi:10.1093/jac/dkv173

25. García-de-Lorenzo A, Luque S, Grau S, et al. Comparative population plasma and tissue pharmacokinetics of micafungin in critically ill patients with severe burn injuries and patients with complicated intra-abdominal infection. Antimicrob Agents Chemother. 2016;60:5914-5921. doi:10.1128/AAC.00727-16

26. Shields RK, Nguyen MH, Press EG, Clancy CJ. Abdominal candidiasis is a hidden reservoir of echinocandin resistance. Antimicrob Agents Chemother. 2014;58:7601-7605. doi:10.1128/AAC.04134-14

27. Ferriols-Lisart R, Aguilar G, Pérez-Pitarch A, Puig J, Ezquer-Gar ín C, Alós M. Plasma concentrations of caspofungin in a critically ill patient with morbid obesity. Crit Care. 2017;21(1):200. doi:10.1186/ s13054-017-1686-1

28. Nguyen TH, Hoppe-Tichy T, Geiss HK, et al. Factors influencing caspofungin plasma concentrations in patients of a surgical intensive care unit. J Antimicrob Chemother. 2007;60(1):100-106. doi:10.1093/ $\mathrm{jac} / \mathrm{dkm} 125$

29. Kovács R, Gesztelyi R, Berényi R, et al. Killing rates exerted by caspofungin in 50\% serum and its correlation with in vivo efficacy in a neutropenic murine model against Candida krusei and C. inconspicua. J Med Microbiol. 2014;63:186-194. doi:10.1099/jmm.0.066381-0

30. Domán M, Kovács R, Perlin DS, et al. Dose escalation studies with caspofungin against Candida glabrata. J Med Microbiol. 2015;64:998-1007.

31. Doman M, Kovacs R, Kardos G, et al. Killing rates of caspofungin in 50 percent serum correlate with caspofungin efficacy against Candida albicans in a neutropenic murine model. Curr Drug Deliv. 2016;13:255-264.
32. Bayegan S, Majoros L, Kardos G, et al. In vivo studies with a Candida tropicalis isolate exhibiting paradoxical growth in vitro in the presence of high concentration of caspofungin. J Microbiol. 2010;48(2):170-173. doi:10.1007/s12275-010-9221-y

33. Brzankalski GE, Najvar LK, Wiederhold NP, et al. Evaluation of aminocandin and caspofungin against Candida glabrata including isolates with reduced caspofungin susceptibility. $J$ Antimicrob Chemother. 2008;62:1094-1100. doi:10.1093/jac/dkn304

34. Gumbo T, Drusano GL, Liu W, et al. Once-weekly micafungin therapy is as effective as daily therapy for disseminated candidiasis in mice with persistent neutropenia. Antimicrob Agents Chemother. 2007;51(3):968-974. doi:10.1128/AAC.01337-06

35. Najvar LK, Bocanegra R, Wiederhold NP, et al. Therapeutic and prophylactic efficacy of aminocandin (IP960) against disseminated candidiasis in mice. Clin Microbio Infect. 2008;14:595-600. doi:10.1111/j.1469-0691.2008.01994.x

36. Zhao Y, Prideaux B, Nagasaki Y, et al. Unraveling drug penetration of echinocandin antifungals at the site of infection in an intra-abdominal abscess model. Antimicrob Agents Chemother. 2017;61(10):e01009-e17. doi:10.1128/AAC.01009-17

37. Bellmann R, Smuszkiewicz P. Pharmacokinetics of antifungal drugs: practical implications for optimized treatment of patients. Infection. 2017;45(6):737-779. doi:10.1007/s15010-017-1042-Z

38. Ben-Ami R, Garcia-Effron G, Lewis RE, et al. Fitness and virulence costs of Candida albicans FKS1 hot spot mutations associated with echinocandin resistance. $J$ Infect Dis. 2011;204(4):626-635. doi:10.1093/infdis/jir351

39. Wiederhold NP, Najvar LK, Bocanegra RA, Kirkpatrick WR, Patterson TF. Caspofungin dose escalation for invasive candidiasis due to resistant Candida albicans. Antimicrob Agents Chemother. 2011;55:3254-3260. doi:10.1128/AAC.01750-10

40. CANCIDAS, INN-caspofungin (as acetate)-Europa EU. Available from: https://ec.europa.eu/health/documents/../2015/../anx_ 132168 en.pdf.

41. Hope WW, Drusano GL. Antifungal pharmacokinetics and pharmacodynamics: bridging from the bench to bedside. Clin Microbiol Infect. 2009;15:602-612. doi:10.1111/j.1469-0691.2009.02913.x

42. Cornely OA, Vehreschild JJ, Vehreschild MJ, et al. Phase II dose escalation study of caspofungin for invasive aspergillosis. Antimicrob Agents Chemother. 2011;55:5798-5803. doi:10.1128/ AAC.05134-11
Infection and Drug Resistance

\section{Publish your work in this journal}

Infection and Drug Resistance is an international, peer-reviewed openaccess journal that focuses on the optimal treatment of infection (bacterial, fungal and viral) and the development and institution of preventive strategies to minimize the development and spread of resistance. The journal is specifically concerned with the epidemiology of

\section{Dovepress}

antibiotic resistance and the mechanisms of resistance development and diffusion in both hospitals and the community. The manuscript management system is completely online and includes a very quick and fair peerreview system, which is all easy to use. Visit http://www.dovepress.com/ testimonials.php to read real quotes from published authors. 